of the northern star, $\lambda$ Cephei, was found by the writer to be identical with that of 5 Puppis.

$23^{\mathrm{h}} 58^{\mathrm{m}} \cdot 3$. The hydrogen line $H \beta$ is bright and super- posed upon a broad dark line. The lines $H \gamma, H \delta$, and $H \varepsilon$ are narrow, and two other narrow lines having the approximate wavelengths 416 and 420 are also present.

The variability of C.P.D. $-73^{\circ} I_{1} 3_{4}, \mathrm{RA} .=13^{\mathrm{h}} 13^{\mathrm{m}} \cdot 5$, Decl. $=-73^{\circ} 55^{\prime}$ (1900), constellation Musca, suspected by Kapteyn (Cape Annals vol. IX p. I I B), has been discovered independently by Miss $\mathcal{L}$. $D$. Wells, and shows a range of about a magnitude and a half.

Harvard College Observatory, 1904 Dec. 21.

Edward C. Pickering.

Oppositions-Ephemeride des Planeten (92) Undina.

\begin{tabular}{|c|c|c|c|c|c|c|c|c|}
\hline \multicolumn{2}{|c|}{1905} & \multicolumn{2}{|c|}{$\alpha$} & \multicolumn{3}{|c|}{$\delta$} & $\log A$ & Ab.-Z. \\
\hline \multirow{2}{*}{\multicolumn{2}{|c|}{ Febr. 27}} & I I $43^{\mathrm{h}}$ & $49^{s} \cdot 5^{2}$ & $+\mathrm{r} 5^{\circ}$ & $18^{\prime}$ & $44 " 9$ & 0.397802 & $20^{m} 46^{s}$ \\
\hline & & 43 & 9.88 & I 5 & 25 & 0.5 & 397232 & 44 \\
\hline \multirow[t]{14}{*}{ März } & $\mathbf{I}$ & 42 & 29.74 & I 5 & $3 \mathrm{I}$ & 13.5 & $39^{67} \times 3$ & 43 \\
\hline & 2 & $4 I$ & 49.10 & I 5 & 37 & 23.8 & 396245 & $4 I$ \\
\hline & 3 & $4 I$ & 8.03 & I 5 & 43 & 30.7 & 395828 & 40 \\
\hline & 4 & 40 & 26.56 & I 5 & 49 & 34.1 & 395463 & 39 \\
\hline & 5 & 39 & 44.67 & I 5 & 55 & $33 \cdot 7$ & 395 I $5^{\circ}$ & $3^{8}$ \\
\hline & 6 & & $2.4^{\circ}$ & 16 & I & $29 \cdot 3$ & 394888 & 37 \\
\hline & 7 & 38 & $19.8 \mathrm{I}$ & r 6 & 7 & 20.5 & 394679 & 37 \\
\hline & 8 & 37 & 36.97 & I 6 & I 3 & 7.0 & 394522 & 36 \\
\hline & 9 & 36 & 53.87 & 16 & I 8 & 48.2 & $3944 \times 7$ & $3^{6}$ \\
\hline & Io & 36 & 10.57 & 16 & 24 & 23.9 & 394364 & 36 \\
\hline & I I & 35 & 27.11 & I 6 & 29 & 53.9 & $3943^{6} 3$ & $3^{6}$ \\
\hline & I 2 & 34 & 43.53 & 16 & 35 & I 7.9 & 394414 & 36 \\
\hline & I 3 & 33 & 59.91 & I 6 & 40 & 35.5 & $3945 \times 6$ & $3^{6}$ \\
\hline & I 4 & 33 & 16.29 & I 6 & 45 & 46.4 & 394671 & 37 \\
\hline \multirow[t]{3}{*}{8} & 15 & 32 & 32.69 & 16 & 50 & 50.5 & 394876 & 37 \\
\hline & 16 & 31 & 49.17 & I 6 & 55 & 47.5 & $395^{1} 33$ & $3^{8}$ \\
\hline & 17 & I I $3 x$ & 5.77 & +17 & 0 & $37 \cdot 3$ & $0.39544^{\circ}$ & $20 \quad 39$ \\
\hline
\end{tabular}

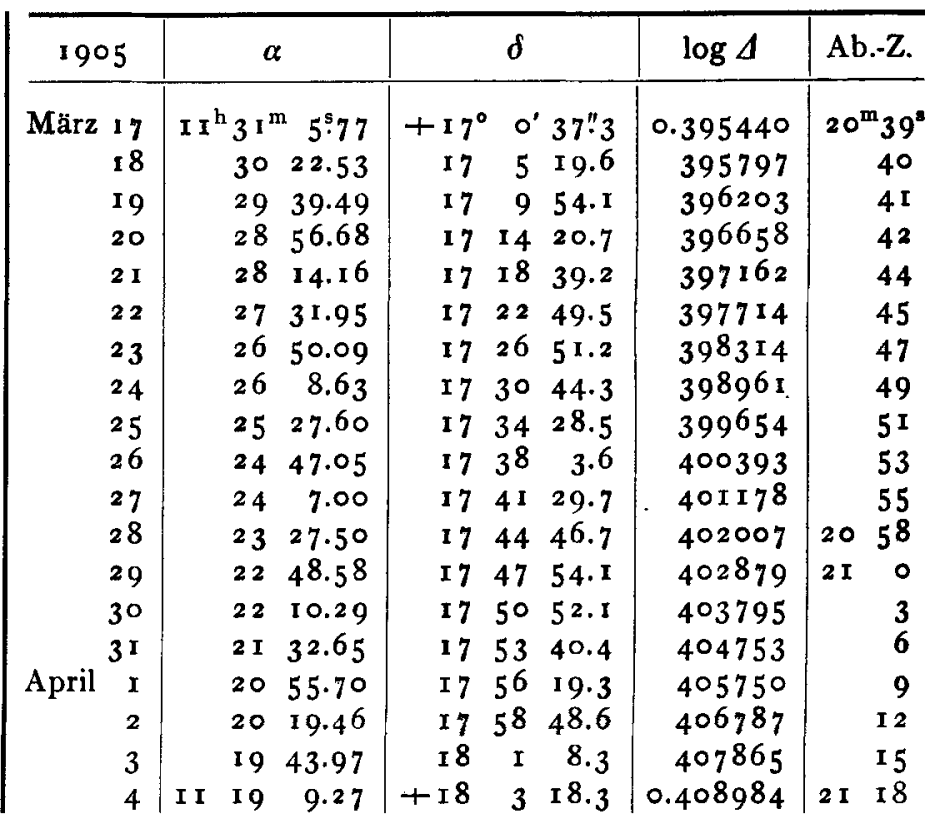

Halmstad in Schweden, 1904 Dez. 7.

Fredrik Anderson.

\title{
Elemente und Ephemeride des Planeten (522) [1904 NC].
}

Das folgende Elementensystem ist basiert auf den beiden Heidelberger photographischen Beobachtungen I 904 Januar ro und Februar 7 , und der Wiener Beobachtung Februar 22. Die Rechnung wurde nach der Enckeschen Methode ausgeführt.
Epoche 1904 Jan. 10.5 M. Z. Berlin.

$$
\begin{aligned}
& M=323^{\circ} \text { I } 0^{\prime} \text { I I."9 } \\
& \omega=474039.4 \\
& \Omega=1194725.8 \text { 1904. } \quad \mu=461 \% 6567 \\
& \left.i=\begin{array}{rll}
227 & \text { I9.1 }
\end{array}\right\}^{1904.0 .} \log a=0.590458
\end{aligned}
$$

Aus den Elementen ergibt sich die folgende Ephemeride für I $^{\text {h }}$ M. Z. Berlin.

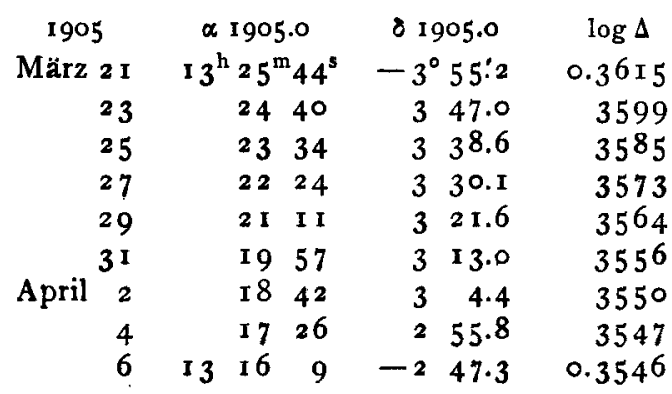

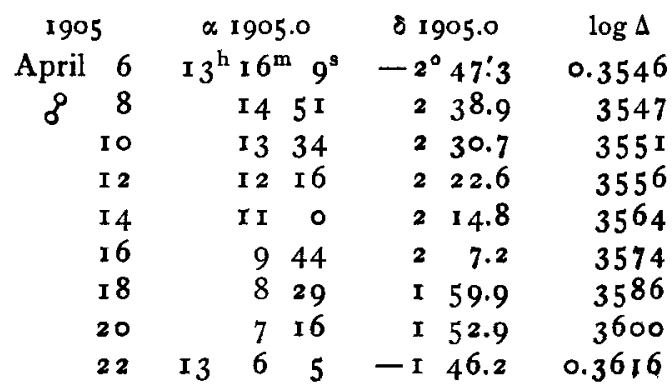

Größe ca. 1 $^{\mathrm{m}}$.

Odense, I904 Dez. I 3 .

Th. Lassen. 